\title{
Genetic Differentiation and Host Specificity Among Populations of Alternaria spp. Causing Brown Spot of Grapefruit and Tangerine × Grapefruit Hybrids in Florida
}

\author{
T. L. Peever, L. Olsen, A. Ibañez, and L. W. Timmer
}

First author: Department of Plant Pathology, Washington State University, Pullman 99164-6430; and second, third, and fourth authors: University of Florida, Citrus Research and Education Center, 700 Experiment Station Road, Lake Alfred 33850.

Current address of L. Olsen: Department of Entomology and Nematology, University of Florida, P.O. Box 110620, Gainesville 32611-0620. Accepted for publication 15 December 1999.

\begin{abstract}
Peever, T. L., Olsen, L., Ibañez, A., and Timmer, L. W. 2000. Genetic differentiation and host specificity among populations of Alternaria spp. causing brown spot of grapefruit and tangerine $\times$ grapefruit hybrids in Florida. Phytopathology 90:407-414.

Alternaria spp. were sampled from brown spot lesions in several geographically separated citrus groves and different grapefruit and tangerine $x$ grapefruit hybrid cultivars in Florida and screened for variation at 16 putative random amplified polymorphic DNA loci. Populations of the pathogen on two hybrids, Minneola and Orlando, in five locations throughout Florida were moderately differentiated (Nei's coefficient of gene differentiation $\left[\mathrm{G}_{\mathrm{ST}}\right]=0.12$ ) among locations. The hypothesis that host-specialized forms of Alternaria spp. cause brown spot on different Citrus spp. and cultivars was tested by estimating genetic differentiation among isolates sampled from different hosts and by pathogenicity assays. Isolates sampled from grapefruit and the hybrid cv. Nova were genetically distinct

tative pathogenicity assays on leaves using spray inoculation revealed that 'Nova' isolates were not significantly more pathogenic on 'Nova' compared with isolates from 'Minneola' and 'Orlando'. Similarly, grapefruit isolates were not significantly more pathogenic on grapefruit compared with isolates from 'Minneola'. Isolates from all hosts had similar disease rankings on each inoculated cultivar, with 'Minneola' the most susceptible, followed in decreasing order of susceptibility by 'Orlando', 'Sunburst', 'Nova', and 'Duncan' grapefruit. Rough lemon was generally immune to all isolates tested; however, occasional brown spot lesions were observed on leaves of this host with isolates from grapefruit. No evidence was found to support the hypothesis that unique genotypes of the pathogen, which are more virulent on 'Sunburst' or grapefruit, have been introduced to Florida. Populations of Alternaria spp. causing brown spot of citrus on grapefruit and 'Nova' in Florida are genetically distinct from isolates on other cultivars, and we speculate that these populations are in the early stages of adaptation to and possible speciation on these hosts.
\end{abstract} from isolates sampled from other hybrid cultivars including Robinson, Sunburst, Minneola, Orlando, and Murcott. No differentiation could be detected among isolates sampled from this latter group of hybrids. Quanti-
Additional keywords: Alternaria alternata, Alternaria citri, polymerase chain reaction, population structure, species specificity.
Brown spot of citrus was first described in Florida on the rootstock cultivar rough lemon (Citrus jambhiri Lush.) in 1937 (28) and on 'Dancy' tangerine (C. reticulata Blanco) in 1974 (41). The disease is currently considered a major problem on many fresh-market citrus cultivars including tangerine $\times$ grapefruit $(C . \times$ paradisi Macfad.) and tangerine $\times$ sweet orange $(C$. sinensis (L.) Osbeck) hybrids. Some of these include 'Minneola', 'Orlando', 'Murcott', 'Nova', 'Osceola', and 'Lee' (38). Lesions can occur on leaves, stems, and fruit and reduce both the yield and marketability of the crop. The disease is difficult to control, and these cultivars require intensive fungicide application programs and careful timing of fungicide sprays to be grown successfully (38). In some locations, the disease has become such a problem that the production of highly susceptible cultivars such as Minneola has been abandoned entirely (39). The citrus brown spot pathogens produce host-specific toxins that are similar in chemical structure to toxins produced by other Alternaria spp. $(16,17,24)$. These toxins are important pathogenicity factors in this disease and likely play a role in controlling host range $(10,15,17,27,41)$.

There appear to be at least three genetically distinct groups of Alternaria spp. that cause foliar diseases of citrus. Each of these groups attacks only a limited number of Citrus spp., and the host ranges do not overlap. The first group is the most economically

Corresponding author: T. L. Peever; E-mail address: tpeever@wsu.edu

Publication no. P-2000-0214-03R

(C) 2000 The American Phytopathological Society important worldwide and causes disease on tangerines, grapefruit, and tangerine $\times$ grapefruit and tangerine $\times$ sweet orange hybrids. This disease was first reported on 'Emperor' mandarin in Australia $(5,14)$ and subsequently identified on 'Dancy' tangerine in Florida (41) and on additional cultivars in several other countries $(3,4,13$, 34,37). Isolates from 'Dancy', 'Emperor', 'Murcott', and 'Minneola' have a wide host range on tangerines and tangerine hybrids $(13,15,27,35)$. Isolates from these cultivars have been referred to collectively as the "tangerine pathotype" (23). A second brown spot pathogen was originally described on rough lemon from South Africa (7) and Florida (28). Isolates from brown spot lesions on rough lemon are highly specific for rough lemon and are known as the "rough lemon pathotype" $(23,26)$. The only other known host for rough lemon isolates is 'Rangpur' lime, $C . \times$ limonia Osbeck $(15,28,41)$. Isolates from rough lemon generally do not cause disease on tangerines or tangerine hybrids, and this specificity appears to be controlled by host-specific toxins produced by each pathotype $(10,16,17,23)$. The third disease of citrus caused by Alternaria spp. is called "mancha foliar de los cítricos," which affects Mexican (key) lime (C. aurantiifolia (L.) Swingle) and is weakly pathogenic on other Citrus spp. in Mexico (25). The symptoms of this disease are very different from Alternaria brown spot on tangerines and rough lemon, and the disease is caused by a morphologically distinct species, A. limicola Simmons \& Palm $(25,32)$. This species may have a much wider host range than either the tangerine or rough lemon pathotypes, because the pathogen has been isolated in the field from six species of Citrus including limes, sour orange, sweet orange, and grapefruit (25). 
The taxonomic status of the fungus that causes citrus brown spot is unclear, even though the disease has been known for more than 90 years (5). The pathogen was first identified as A. citri (14), although the original description of $A$. citri was based on a specimen causing a completely different postharvest disease, black rot of citrus (1). Although isolates of A. citri causing black rot appeared to be morphologically similar to isolates that caused brown spot, their pathogenic characteristics and toxin production distinguished them as distinct strains (14). The pathogen was subsequently placed in A. alternata (Fr.:Fr.) Keissl. by Nishimura and Kohmoto (23) based on conidial morphology and conidial measurements published for A. alternata by Simmons (31). The patho-

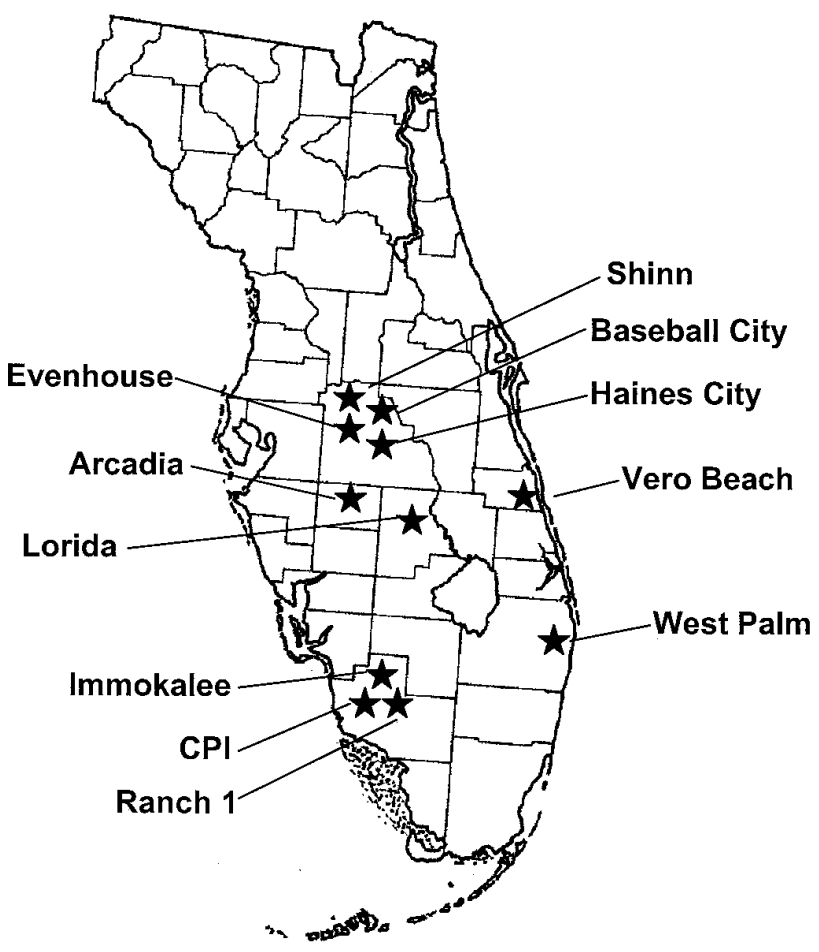

Fig. 1. Sampling locations of Alternaria spp. causing brown spot of citrus in Florida. Details of locations are given in Table 1. gen has also been called A. alternata pv. citri $(34,35)$. Sequencing and restriction fragment length polymorphism studies of mitochondrial DNA and the internal transcribed spacer regions of ribosomal DNA have supported a close phylogenetic relationship among the toxin-producing Alternaria spp. from several citrus and noncitrus hosts including Japanese pear, strawberry, and apple, as well as with saprophytic A. alternata (18-20). No comparable molecular systematic studies have been performed with black rot isolates or with a representative sample of brown spot isolates from citrus. Morphotaxonomic studies of citrus brown spot isolates have suggested that the disease is not caused by either A. citri or A. alternata $(32,33)$, and 10 new species of Alternaria have been recently described as causal agents of citrus brown spot in different parts of the world (33). Due to the conflicting morphological and molecular data, we have chosen to describe the isolates sampled in this study as simply Alternaria spp. until their identity can be firmly established.

Many of the grapefruit $\times$ tangerine hybrids that are susceptible to brown spot are offspring of crosses of 'Dancy' tangerine. This has led to speculation that susceptibility to brown spot is inherited from the 'Dancy' parent $(13,15,29)$. This speculation was recently confirmed with experimental crosses and host inoculations, and it appears that resistance to brown spot is inherited as a single recessive gene (6). Host response to brown spot is quite variable among closely related hybrids (T. L. Peever, unpublished data), suggesting that other genes are likely involved in this interaction. One cultivar with 'Dancy' parentage, Sunburst, initially appeared to be quite resistant to the disease in Florida. 'Sunburst' resulted from a cross between 'Robinson' and 'Osceola', both of which have a 'Dancy' grandparent. Within the last few years, reports of severe brown spot have been reported on 'Sunburst' (39). The lesions that were observed on 'Sunburst' were comparable to those on 'Minneola', and it has been hypothesized that a new strain of the pathogen that is more virulent on 'Sunburst' may have been introduced into Florida.

Despite extensive plantings of grapefruit in Florida, Alternaria brown spot has only recently been reported on this host in Florida (39). Brown spot is an economically important problem on grapefruit in Israel and South Africa $(30,35,39)$ and has also been reported in Australia $(14,27)$. In Florida, lesions have been observed only on the fruit, while in Israel and South Africa, the pathogen affects both leaves and fruit, even though many of the same cultivars are grown in all of these locations. Grapefruit leaves are susceptible to the pathogen in artificial inoculation studies $(10,27,35)$, and isolates from grapefruit are known to cause disease on tangerines and hy-

TABLE 1. Isolates of Alternaria spp. sampled from different locations and hosts in Florida

\begin{tabular}{|c|c|c|c|c|c|}
\hline Location $^{\mathrm{a}}$ & Sample name & Host & Tissue & $n$ & Collection date \\
\hline \multirow[t]{2}{*}{ Shinn Grove, Polk City } & \multirow[t]{2}{*}{ Shinn $^{\mathrm{b}}$} & 'Minneola' & Leaf & 37 & $08 / 96$ \\
\hline & & 'Robinson' & Leaf & 14 & $09 / 96$ \\
\hline \multirow[t]{2}{*}{ Shinn Grove, Evenhouse Road, Lake Alfred } & \multirow[t]{2}{*}{ Evenhouse $^{b}$} & 'Minneola' & Leaf & 27 & $09 / 96$ \\
\hline & & 'Robinson' & Leaf & 10 & $09 / 96$ \\
\hline Callery-Judge Grove, West Palm Beach & West Palm & 'Minneola' & Leaf & 11 & $10 / 96$ \\
\hline \multirow[t]{4}{*}{ CPI, Inc., Immokalee } & \multirow[t]{4}{*}{ CPI } & 'Minneola' & Leaf & 28 & $11 / 96$ \\
\hline & & 'Murcott' & Leaf & 30 & $11 / 96$ \\
\hline & & 'Orlando' & Leaf & 27 & $11 / 96$ \\
\hline & & 'Nova' & Leaf & 13 & $11 / 96$ \\
\hline \multirow[t]{3}{*}{ SWFREC, Immokalee } & \multirow[t]{3}{*}{ Immokalee } & 'Minneola' & Leaf & 29 & 03/97 \\
\hline & & 'Orlando' & Leaf & 35 & $03 / 97$ \\
\hline & & 'Nova' & Leaf & 22 & 03/97 \\
\hline \multirow[t]{2}{*}{ McCullough Grove, Lorida } & \multirow[t]{2}{*}{ Lorida } & 'Sunburst' & Leaf & 26 & $04 / 97$ \\
\hline & & 'Orlando' & Leaf & 14 & $04 / 97$ \\
\hline \multirow[t]{2}{*}{ Ranch 1 Co-op, Immokalee } & \multirow[t]{2}{*}{ Ranch 1} & 'Sunburst' & Leaf & 13 & $04 / 97$ \\
\hline & & 'Orlando' & Leaf & 17 & $04 / 97$ \\
\hline \multirow[t]{2}{*}{ Carlton $2 \times 4$ Ranch, Arcadia } & \multirow[t]{2}{*}{ Arcadia } & 'Sunburst' & Leaf & 33 & $07 / 97$ \\
\hline & & 'Orlando' & Leaf & 24 & $07 / 97$ \\
\hline \multirow[t]{2}{*}{ Hammond Grove, Vero Beach } & \multirow[t]{2}{*}{ Vero Beach } & 'Marsh' grapefruit & Fruit & 20 & 07/97 \\
\hline & & 'Flame' grapefruit & Fruit & 16 & $07 / 97$ \\
\hline Baseball City & Baseball City ${ }^{b}$ & Rough lemon & Leaf & 39 & $05 / 97$ \\
\hline Haines City & Haines City ${ }^{\mathrm{b}}$ & Rough lemon & Leaf & 22 & $03 / 97$ \\
\hline
\end{tabular}

a Sampling location pictured in Figure 1.

b Isolates sampled for a previous study (26). 
brids $(14,35)$. Studies involving purified toxins from tangerine isolates have also demonstrated the susceptibility of grapefruit $(10,13$, 15). The recent appearance of brown spot on grapefruit in Florida has lead to the speculation that either the pathogen has evolved increased virulence on grapefruit or that there has been an introduction of a new genotype that is specific for this host into Florida.

In a previous study, isolates of Alternaria spp. sampled from rough lemon and 'Minneola' tangelo were highly specific for the hosts from which they were originally isolated (26). It is unknown if a similar specificity exists among isolates from grapefruit, tangerines, and tangerine hybrids. Although many Citrus spp. and cultivars are considered susceptible to brown spot, disease reactions vary considerably and it is possible that each host may provide a slightly different selective regime for brown spot pathogens. Many citrus hosts susceptible to brown spot in Florida are grown commercially in small blocks. This proximity of different host genotypes provided a good opportunity to test the hypothesis of host specificity of Alternaria spp. on these cultivars. The objective of this study was to determine the population structure and host specificity of Alternaria spp. on grapefruit and tangerine $\times$ grapefruit hybrids. Specific hypotheses tested were (i) that isolates sampled from 'Minneola' or 'Orlando' from five different geographic locations in Florida were genetically differentiated; (ii) that isolates causing brown spot on grapefruit were genetically distinct from those causing disease on other hybrids; (iii) that isolates sampled from 'Minneola', 'Orlando', 'Murcott', 'Nova', 'Robinson', and 'Sunburst' growing in close proximity in small blocks were host specific; and (iv) that novel genotypes of the pathogen have been introduced into Florida that were specific for grapefruit and 'Sunburst'.

\section{MATERIALS AND METHODS}

Sampling. Isolates of Alternaria spp. were obtained from infected leaves and fruit of eight citrus cultivars in nine locations throughout Florida (Fig. 1; Table 1). Trees were randomly sampled (one isolate per tree) from a $2,500-\mathrm{m}^{2}$ area within each grove. Isolations were made from young lesions (less than $2 \mathrm{~mm}$ in diameter) on new leaves. Isolates were cultured and single-conidial isolates collected and stored as previously described (26). Two sampling strategies were employed to address different subobjectives: (i) isolates were collected from 'Minneola' and 'Orlando' in five locations to determine the population genetic structure of the pathogen on two representative hosts over the entire citrusgrowing area of Florida; and (ii) isolates were collected from different citrus cultivars growing in the same location to test the hy- pothesis of host specialization of the pathogen. The genetic relationships among the citrus cultivars sampled in this study are illustrated in Figure 2. Isolates sampled from 'Minneola' in the Shinn and Evenhouse locations and rough lemon isolates from Baseball City and Haines City were collected for a previous study (26).

Pathogenicity. The pathogenic specialization of isolates from grapefruit and 'Nova' was determined by spraying spore suspensions onto leaves of various citrus hosts detached from trees grown in a greenhouse (26). Quantitative comparisons of pathogenicity were performed to test the hypothesis that isolates from grapefruit and 'Nova' were more pathogenic on the hosts they were isolated from relative to isolates from other tangerine $\times$ grapefruit hybrids. Conidia were produced and washed using centrifugation as previously described (26), adjusted to $1 \times 10^{4}$ per $\mathrm{ml}$ using a haemocytometer, and sprayed to runoff using a thin-layer chromatography sprayer (Crown Tools, Woodstock, IL). Detached leaves (four leaves per treatment) were inoculated in 2-ml microcentrifuge tubes as previously described (26) and incubated for $24 \mathrm{~h}$ at $25^{\circ} \mathrm{C}$ in moist chambers. Disease incidence was assessed quantitatively by counting the number of lesions per leaf $24 \mathrm{~h}$ after inoculation. Two experiments were performed with arbitrarily selected isolates, one to test the host specificity of isolates from 'Nova' and another to test the specificity of isolates from grapefruit. Experiment 1 consisted of seven isolates randomly selected from 'Nova', 'Minneola', and 'Orlando' in two locations (CPI and Immokalee). Isolates were inoculated on 'Nova', 'Minneola', and 'Orlando'. Experiment 2 was performed similarly, except that it consisted of a sample of 14 isolates from 'Marsh' and 'Flame' grapefruit in one location (Vero Beach) and 13 isolates from 'Minneola' in two locations (Shinn and Evenhouse). Isolates for experiment 2 were inoculated on 'Minneola', 'Sunburst', 'Orlando', 'Duncan' grapefruit, and rough lemon. Data were analyzed as two-factor-crossed designs (host of original isolation = "Isolate" and host inoculated = "Host"), with Isolate a random factor and Host a fixed factor. Analysis of variance (ANOVA) was performed using the GLM procedure of Minitab version 12 statistical software (Minitab Inc., State College, PA). Preliminary residual plot analyses indicated nonconstancy of error variance (i.e., variance increased as number of lesions per leaf increased), and all ANOVA were subsequently performed with $\log _{e}$-transformed data. A significant Isolate $\times$ Host interaction effect at $P<0.05$ in the ANOVA was considered evidence for pathogenic specialization.

DNA extraction. DNA was extracted as described previously (26). Briefly, lyophilized, powdered mycelium (approximately $50 \mu \mathrm{g}$ ) was extracted using a lysis buffer containing $50 \mathrm{mM}$ EDTA, $100 \mathrm{mM}$

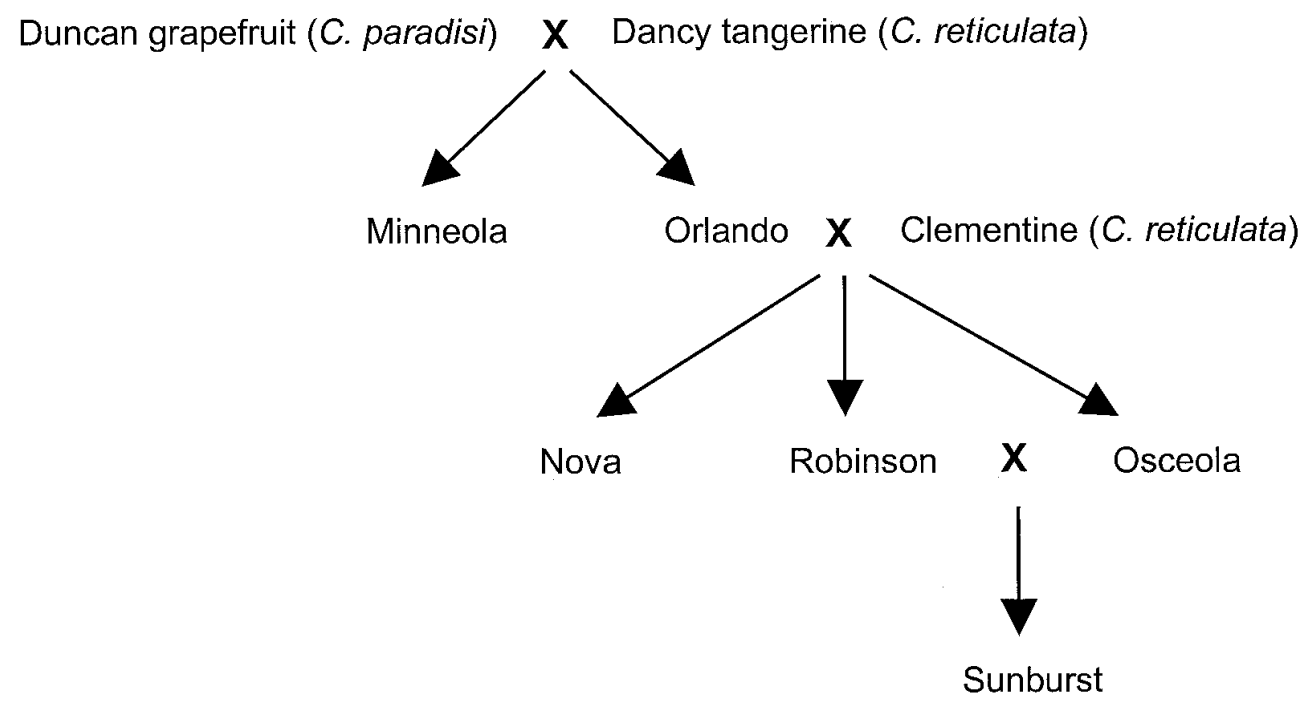

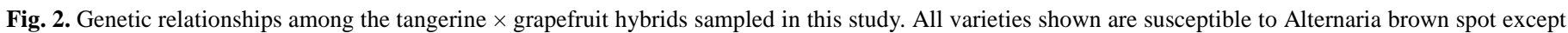

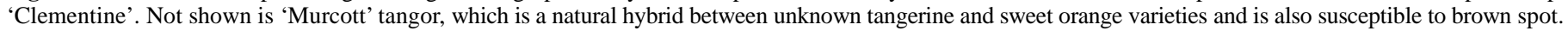


Tris buffer ( $\mathrm{pH} \mathrm{8)}$, and $3 \%$ sodium dodecyl sulfate for 30 to $45 \mathrm{~min}$ at $65^{\circ} \mathrm{C}$. Mycelium was pelleted by centrifugation and the supernatant precipitated with $8 \mathrm{M}$ potassium acetate at $-20^{\circ} \mathrm{C}$ for $15 \mathrm{~min}$. Following centrifugation, the supernatant was subjected to two rounds of phenol/chloroform/isoamyl alcohol $(25: 24: 1)$ extraction and one round of chloroform/isoamyl alcohol (24:1) extraction. The final supernatant was precipitated with two volumes of $100 \% \mathrm{EtOH}$ and $0.5 \mathrm{M} \mathrm{NaCl}$. Pellets were resuspended in water, precipitated again in $14 \%$ polyethylene glycol and $1 \mathrm{M} \mathrm{NaCl}$, and resuspended in $50 \mu \mathrm{l}$ of Tris-EDTA buffer (10 mM Tris and $1 \mathrm{mM}$ EDTA). RNA was digested with $20 \mu \mathrm{g}$ of RNase A (Sigma Chemical Co., St. Louis) per $\mathrm{ml}$ at $37^{\circ} \mathrm{C}$ for $3 \mathrm{~h}$. DNA concentrations were estimated visually in ethidium bromide-stained agarose gels by comparing band intensity with known quantities of phage lambda DNA (Life Technologies Inc., Rockville MD). At least three independent DNA extractions were made from each of several selected isolates to verify the repeatability of the polymerase chain reactions (PCRs) among different extractions (26).

Random amplified polymorphic DNA (RAPD) markers. Fifteen-microliter PCRs with random 10-nucleotide primers were performed in 96-well microtiter plates as described previously (26). Reaction mixtures contained 25 to $50 \mathrm{ng}$ of DNA ( $1 \mu \mathrm{l}$ of diluted DNA), $1.5 \mu \mathrm{l}$ of $10 \times$ reaction buffer, $200 \mu \mathrm{M}$ dNTPs (Idaho Technologies, Idaho Falls, ID), $0.8 \mu \mathrm{M}$ primer (Operon Technologies, Inc., Alameda, CA), and 0.6 units of Taq polymerase (Sigma Chemical Co.; Promega Corp., Madison, WI; or Life Technologies Inc.). Mixtures were overlain with $40 \mu \mathrm{l}$ of sterile light mineral oil and placed on a thermocycler (MJ Research Inc., Watertown, MA). Cycling conditions included an initial 2 -min melt at $93^{\circ} \mathrm{C}$ followed by 44 cycles of $92^{\circ} \mathrm{C}$ for $1 \mathrm{~min}$ (melt), $37^{\circ} \mathrm{C}$ for $1 \mathrm{~min}$ (anneal), and $72^{\circ} \mathrm{C}$ for $2 \mathrm{~min}$ (extension). The final cycle was $92^{\circ} \mathrm{C}$ for $1 \mathrm{~min}, 37^{\circ} \mathrm{C}$ for $1 \mathrm{~min}$, and $72^{\circ} \mathrm{C}$ for $8 \mathrm{~min}$. PCR products were separated in $1.8 \%$ agarose gels with HindIII/EcoRI-digested lambda DNA (Promega Corp.) as size standards and visualized with a digital imaging system (UltraViolet Products, Upland, CA). RAPD markers were selected as described previously (26). The reproducibility of the RAPD markers was tested by performing PCRs with different concentrations ( 2 to $200 \mathrm{ng}$ ) of DNA template, with at least three independent DNA extractions from the same isolate and different sources of Taq polymerase (Sigma Chemical Co., Promega Corp., and Life Technologies Inc.). Identical RAPD bands were obtained with all treatments.

RAPD data analysis. RAPD PCR products were scored as genetic data with positive (band present) and negative (band absent) alleles at 16 putative genetic loci as described previously (26). These data were used to estimate allele frequencies and standard population genetic statistics with POPGENE population genetics software (POPGENE, version 1.21; Molecular Biology and Biotechnology Centre, University of Alberta, Edmonton, Canada). Heterogeneity in allele frequencies among populations of isolates sampled from 'Minneola' and 'Orlando' in five locations was tested with the likelihood ratio chi-square statistic $\left(\mathrm{G}^{2}\right)(2,11)$, and genetic differentiation among locations and cultivars was estimated using Nei's coefficient of gene differentiation $\left(\mathrm{G}_{\mathrm{ST}}\right)(22)$. The null hypothesis of no differentiation among locations or among cultivars $\left(\mathrm{G}_{\mathrm{ST}}=0\right)$ was tested using a Monte Carlo randomization approach $(12,36)$ that tested the observed $\mathrm{G}_{\mathrm{ST}}$ against a null distribution of $\mathrm{G}_{\mathrm{ST}}$. The null distribution of $\mathrm{G}_{\mathrm{ST}}$ was generated by randomly assigning isolates to locations or cultivar without replacement 1,000 times and calculating a $G_{\mathrm{ST}}$ value after each iteration. The null hypothesis was rejected if fewer than 50 of the simulated $\mathrm{G}_{\mathrm{ST}}$ values $(P=0.05)$ exceeded the observed $\mathrm{G}_{\mathrm{ST}}$. Phenograms were generated in NTSYSpc (Numerical Taxonomy and Multivariate Analysis System, version 2.0; Exeter Software, Setauket, NY) using genetic distances among samples of isolates from locations or cultivars. Distances were calculated with the SIMGEND program, in which each population sample (from a location or from a cultivar) was treated as the operational taxonomic unit. Genetic similarity matrices in SIMGEND were estimated from RAPD allele frequencies using Nei's (21) maximum genetic distance and clustering was performed with

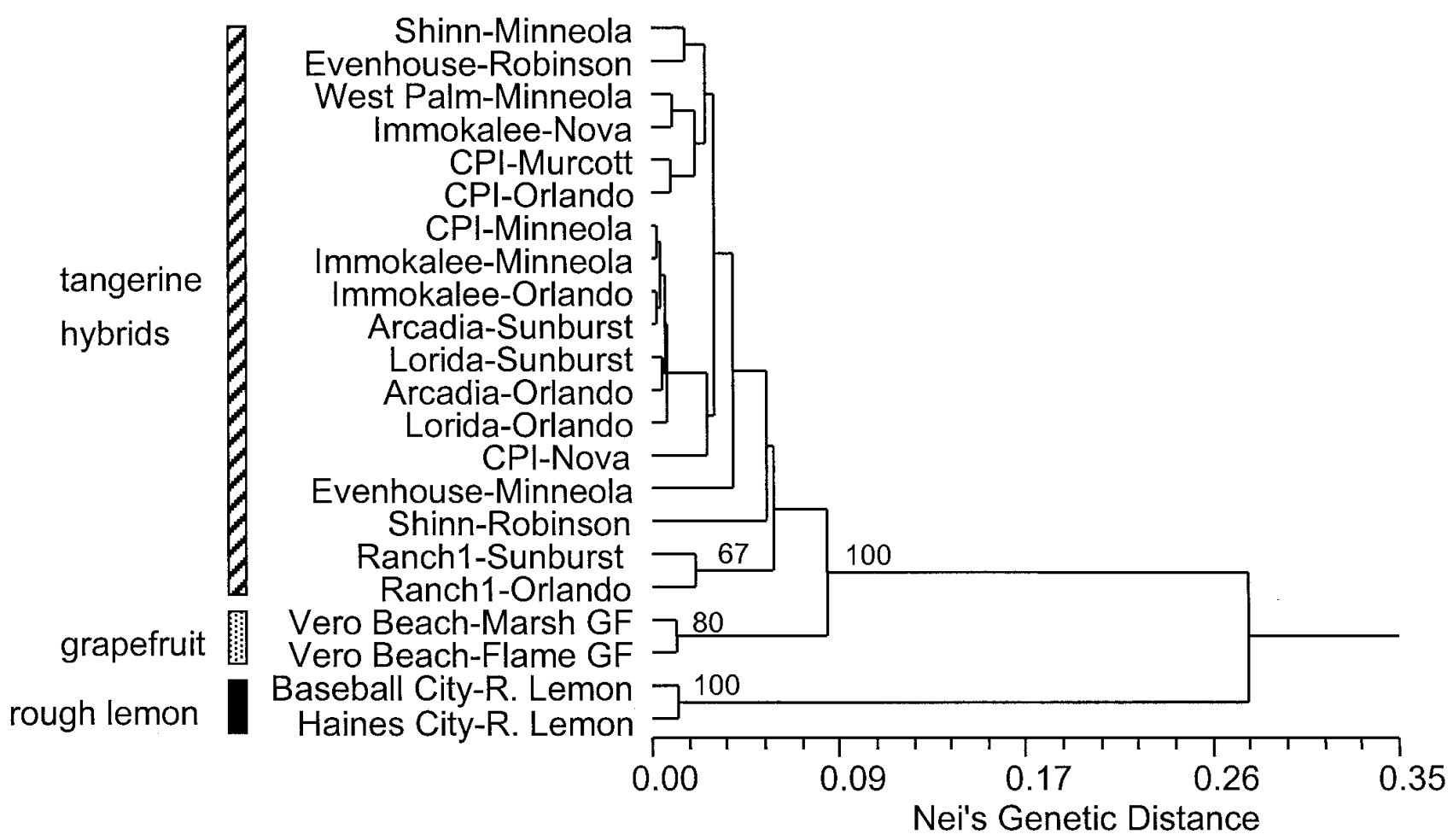

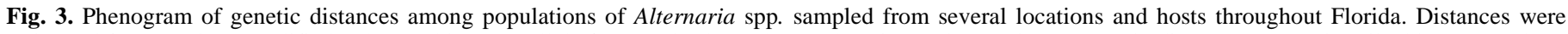
estimated from random amplified polymorphic DNA allele frequencies in each sample using Nei's maximum genetic distance (21) as described in text. Isolates sampled previously from two populations of rough lemon $(\mathrm{BC} 2$ and $\mathrm{HC} 2)$ were included as outgroups. Numbers at the major branches indicate the percentage of occurrence of the cluster to the right of the branch in 1,000 bootstrapped dendrograms. Only branches occurring in 50\% or more of the bootstrapped dendrograms (i.e., majority rule consensus tree) are shown. 
the SAHN program with an unweighted pair group method with arithmetic means (UPGMA) algorithm. Statistical support for dendrogram branches was obtained by generating a majority-rule consensus tree in PHYLIP (Phylogeny Inference Package, version 3.5c; Department of Genetics, University of Washington, Seattle) using the SEQBOOT, GENDIST, NEIGHBOR, and CONSENSE programs with 1,000 bootstrapped samples.

\section{RESULTS}

Genetic differentiation of grapefruit isolates. Populations of Alternaria spp. sampled from 'Marsh' and 'Flame' grapefruit were highly differentiated from populations sampled from tangerine $\times$ grapefruit hybrids throughout Florida (Fig. 3). Grapefruit populations (VB-WGF and VB-RGF) clustered together in the phenogram, and the genetic distance between grapefruit and the hybrid isolates was approximately 0.09 (Fig. 3). This differentiation was much lower than that obtained between samples from rough lemon (BC2-RLR and HC2-RLR) and the hybrids (Fig. 3). The grapefruit isolate cluster in the phenogram was moderately well supported with a bootstrap value of $80 \%$ (Fig. 3). Differentiation between the grapefruit isolates and a pooled sample of isolates from 'Minneola' from across Florida was estimated using Nei's $\mathrm{G}_{\mathrm{ST}}$ (Table 2). The pooled sample of 'Minneola' isolates was used to avoid the potentially confounding effects of host and location, as grapefruit was the only host sampled in Vero Beach. This analysis revealed that the grapefruit isolates were strongly differentiated from the 'Minneola' isolates. No significant genetic differentiation was found between samples of isolates from 'Marsh' versus 'Flame' grapefruit (Fig. 3; Table 2).

Specificity of tangerine $\times$ grapefruit hybrid isolates with RAPDs. Populations of Alternaria spp. from hybrid hosts in different locations in Florida were not strongly differentiated (Fig. 3). A much lower level of genetic differentiation among locations and hosts was observed relative to that found between rough lemon and the hybrids (Fig. 3). Populations of the pathogen sampled from 'Sunburst' and 'Orlando' at the Ranch 1 location were differentiated with a relatively low bootstrap value of $67 \%$ (Fig. 3). All other populations sampled from hybrids in Florida had bootstrap values below $50 \%$ and could not be differentiated using this analysis (Fig. 3). Gene diversity analyses (genetic distances and Nei's $\mathrm{G}_{\mathrm{ST}}$ ) of isolates sampled from different cultivars within locations revealed significant genetic differentiation among isolates from different hosts (Tables 2 and 3; Fig. 4). Isolates sampled from 'Minneola', 'Orlando', 'Murcott', and 'Nova' in the CPI location and 'Minneola', 'Orlando', and 'Nova' in the Immokalee location were significantly differentiated (Tables 2 and 3; Fig. 4). Pairwise

TABLE 2. Pairwise comparisons of $\mathrm{G}_{\mathrm{ST}}$ values between hosts in the CPI, Immokalee, and Vero Beach locations

\begin{tabular}{lllllll}
\hline & & \multicolumn{4}{c}{ Host } \\
\cline { 3 - 6 } Location & Host & 'Orlando' & 'Murcott' & 'Nova' & $\begin{array}{c}\text { 'Marsh' } \\
\text { grapefruit }\end{array}$ & $\begin{array}{c}\text { 'Flame' } \\
\text { grapefruit }\end{array}$ \\
\hline CPI & 'Minneola' & $0.055^{* \mathrm{a}}$ & $0.032^{\mathrm{ns}}$ & $0.078^{*}$ & & \\
& 'Orlando' & & $0.036^{\mathrm{ns}}$ & $0.047^{\mathrm{ns}}$ & & \\
& 'Murcott' & & & $0.087^{*}$ & & \\
Immokalee & 'Minneola' & $0.011^{\mathrm{ns}}$ & & $0.109^{*}$ & & \\
& 'Orlando' & & $0.098^{* *}$ & & \\
\multirow{2}{*}{ Vero Beach } & 'Minneola'b & & & $0.084^{*}$ & $0.133^{* *}$ \\
& 'Marsh' \\
& grapefruit & & & & $0.015^{\mathrm{ns}}$ \\
\hline
\end{tabular}

${ }^{\text {a }}$ Genetic diversity between hosts as a proportion of total diversity. $\mathrm{G}_{\mathrm{ST}}=\left(\mathrm{H}_{\mathrm{T}}-\right.$ $\mathrm{H}_{\mathrm{S}}$ )/ $\mathrm{H}_{\mathrm{T}}$, in which $\mathrm{H}_{\mathrm{T}}$ is the overall gene diversity (over both hosts) and $\mathrm{H}_{\mathrm{S}}$ is the gene diversity within each host (22). Null hypothesis of $\mathrm{G}_{\mathrm{ST}}=0$ among hosts. ${ }^{\text {ns }}=P>0.05 ; *=P<0.05$; and $* *=P<0.01$, estimated using Monte Carlo simulations as described in text.

b Isolates pooled from five locations throughout Florida including Shinn, Evenhouse, CPI, Immokalee, and West Palm $(n=132)$. comparisons of $\mathrm{G}_{\mathrm{ST}}$ values among cultivars revealed that most of the differentiation was due to isolates sampled from 'Nova' (Table 2). Populations sampled from 'Minneola' and 'Robinson' were significantly differentiated in one location (Shinn) but not in the other (Evenhouse) (Table 3). Isolates from 'Sunburst' could not be differentiated from isolates collected from 'Orlando' in three sampling locations (Table 3) or from isolates collected from any other hybrid (Fig. 3). Many of the same haplotypes were sampled from grapefruit, 'Sunburst', and the other hybrids (data not shown), indicating that disease on grapefruit and 'Sunburst' could not be attributed to a novel genotype that was unique to these cultivars.

Genetic differentiation among isolates from 'Minneola' and 'Orlando' in different locations in Florida. Populations of Alternaria spp. sampled from 'Minneola' in five geographically separated locations in Florida were moderately genetically differentiated. Significant differentiation $\left(\mathrm{G}_{\mathrm{ST}}=0.118, P<0.01\right)$ was observed among isolates sampled from 'Minneola' in five locations (Table 3). Similar levels of differentiation $\left(\mathrm{G}_{\mathrm{ST}}=0.126, P<0.001\right)$ were observed among isolates sampled from 'Orlando' in five locations (Table 3).

Pathogenic specialization on 'Nova' and grapefruit. Isolates from 'Nova' were not significantly more pathogenic on 'Nova' than were isolates from 'Minneola' or 'Orlando' (Fig. 5A; Table 4). Isolates from 'Nova', 'Minneola', and 'Orlando' produced similar levels of disease on each cultivar indicated by the nonsignificant Isolate factor in the ANOVA (Table 4). Lack of host specificity was confirmed by the nonsignificant Isolate $\times$ Host interaction effect in the ANOVA (Table 4). Isolates from 'Marsh' and 'Flame' grapefruit were not significantly more pathogenic on 'Duncan' grapefruit than were isolates from 'Minneola' (Fig. 5B; Table 4). Iso-

TABLE 3. Genetic differentiation among populations of Alternaria spp. sampled from a single host in multiple locations or from multiple hosts in a single location

\begin{tabular}{|c|c|c|c|c|}
\hline Comparison & Location(s) & Host & $n$ & $\mathrm{G}_{\mathrm{ST}}^{\mathrm{a}}$ \\
\hline \multirow[t]{10}{*}{ Among locations } & Shinn & 'Minneola' & 37 & \\
\hline & Evenhouse & 'Minneola' & 27 & \\
\hline & CPI & 'Minneola' & 28 & \\
\hline & Immokalee & 'Minneola' & 29 & \\
\hline & West Palm & 'Minneola' & 11 & $0.118 * *$ \\
\hline & CPI & 'Orlando' & 27 & \\
\hline & Immokalee & 'Orlando' & 35 & \\
\hline & Lorida & 'Orlando' & 14 & \\
\hline & Ranch 1 & 'Orlando' & 17 & \\
\hline & Arcadia & 'Orlando' & 24 & $0.126^{* * *}$ \\
\hline \multirow{18}{*}{$\begin{array}{l}\text { Among or between } \\
\text { hosts within location }\end{array}$} & & & & \\
\hline & CPI & 'Minneola' & 28 & \\
\hline & CPI & 'Orlando' & 27 & \\
\hline & CPI & 'Murcott' & 30 & \\
\hline & CPI & 'Nova' & 13 & $0.084 *$ \\
\hline & Immokalee & 'Minneola' & 29 & \\
\hline & Immokalee & 'Orlando' & 35 & \\
\hline & Immokalee & 'Nova’ & 22 & $0.106^{* *}$ \\
\hline & Shinn & 'Minneola' & 37 & \\
\hline & Shinn & 'Robinson' & 14 & $0.154 * *$ \\
\hline & Evenhouse & 'Minneola' & 27 & \\
\hline & Evenhouse & 'Robinson' & 10 & $0.053^{\mathrm{ns}}$ \\
\hline & Lorida & 'Sunburst' & 26 & \\
\hline & Lorida & 'Orlando' & 14 & $0.024^{\mathrm{ns}}$ \\
\hline & Ranch 1 & 'Sunburst' & 13 & \\
\hline & Ranch 1 & 'Orlando' & 17 & $0.024^{\mathrm{ns}}$ \\
\hline & Arcadia & 'Sunburst' & 33 & \\
\hline & Arcadia & 'Orlando' & 24 & $0.046^{\mathrm{ns}}$ \\
\hline
\end{tabular}

a Genetic diversity partitioned among locations or among/between hosts as a proportion of total genetic diversity. $\mathrm{G}_{\mathrm{ST}}=\left(\mathrm{H}_{\mathrm{T}}-\mathrm{H}_{\mathrm{S}}\right) / \mathrm{H}_{\mathrm{T}}$, in which $\mathrm{H}_{\mathrm{T}}$ is the overall gene diversity (over all locations or all hosts) and $\mathrm{H}_{\mathrm{S}}$ is the gene diversity within locations or hosts (22). Null hypothesis of $\mathrm{G}_{\mathrm{ST}}=0$ among hosts. $^{\text {ns }}=P>0.05 ; *=P<0.05$; and $* *=P<0.01$, estimated using Monte Carlo simulations as described in text. 
lates from grapefruit and 'Minneola' produced similar levels of disease on each cultivar tested, which was indicated by the nonsignificant Isolate factor in the ANOVA (Table 4), and lack of host specificity was evident in the nonsignificant Isolate $\times$ Host interaction effect in the ANOVA (Table 4). Host was a significant factor in both experiments, indicating significant differences in brown spot susceptibility among cultivars (Table 4). 'Minneola' was the most susceptible, followed by 'Orlando', 'Sunburst', 'Nova', and 'Duncan' grapefruit (Fig. 5). Most of the isolates did not produce lesions on rough lemon, with the exception of one isolate from 'Flame' grapefruit and two isolates from 'Marsh' grapefruit that produced a single lesion each on one of four replicate leaves (data not shown).

\section{DISCUSSION}

Alternaria spp. causing brown spot on grapefruit and 'Nova' were significantly differentiated from populations on other tangerine $\times$ grapefruit hybrids. Despite this genetic differentiation with RAPD markers, we were unable to detect any pathogenic specialization of grapefruit and 'Nova' isolates. Although the level of differentiation was much lower than that previously observed between rough lemon and 'Minneola' tangelo (26), the current results suggest that Alternaria spp. exist as discrete, independently evolving lineages on different citrus cultivars. The differentiation of isolates on 'Nova' and grapefruit was strongly supported by high bootstrap values in the phenogram and by significant $\mathrm{G}_{\mathrm{ST}}$ values between hosts. Most of the Alternaria spp. isolates used in this study were isolated from infected leaf tissue, while the grapefruit isolates were obtained from fruit lesions. Brown spot has never been reported on grapefruit leaves in Florida, but commonly occur on both leaves and fruit in Israel and South Africa $(13,30,35)$. One hypothesis for the differentiation of grapefruit isolates is that these isolates may be tissue specific (i.e., genetic differentiation between "leaf-infecting" and "fruit-infecting" isolates). However, we have never observed any genetic differentiation between isolates from leaves and isolates from fruit, including those sampled from the same trees (T. L. Peever, unpublished data). Therefore, the differentiation we observed between isolates affecting grapefruit and tangerine hybrids is likely the result of selection by the grapefruit host rather than of tissue specificity.

Isolates on 'Nova' tangerine were not differentiated from isolates on 'Murcott', 'Orlando', and 'Minneola' in the overall phenogram, but were easily differentiated when samples of isolates were compared among different citrus cultivars growing within 50 meters of each other in the same grove. The proximity of hosts allowed a more powerful test of host specificity than did a comparison of isolates from different hosts in different geographic regions. 'Nova' is genetically distinct from 'Orlando', 'Minneola', and 'Murcott' because it has 'Clementine' tangerine ( $C$. reticulata) as one of its parents (Fig. 1). 'Clementine' is resistant to brown spot and resistance appears to be recessive (6). 'Nova' was considerably more resistant to brown spot than were 'Minneola', 'Murcott', and 'Orlando' in the spray inoculation studies reported here and may, therefore, provide a different selective regime for the brown spot pathogen compared with other cultivars. 'Robinson' tangerine is a sibling of 'Nova' (Fig. 2), and both 'Robinson' and 'Nova' are more resistant to brown spot in the field than are other hybrids. Early lesions on 'Nova' and 'Robinson' look very similar to those found on 'Minneola', but the lesions do not expand as on other hybrids and they lack yellow halos attributed to toxin production (T. L. Peever, unpublished data). Although 'Robinson' is a sibling of 'Nova' and appears to be similarly resistant to brown spot, no consistent evidence for differentiation of isolates on 'Robinson' was obtained relative to isolates from 'Minneola' in adjacent rows of trees in the same grove.

We were unable to detect significant differences in pathogenicity between 'Nova' and grapefruit isolates on their respective hosts and isolates from other cultivars. This result suggests that isolates from 'Nova' and grapefruit are genetically differentiated in terms of RAPD markers, but not for factors controlling pathogenicity.

A

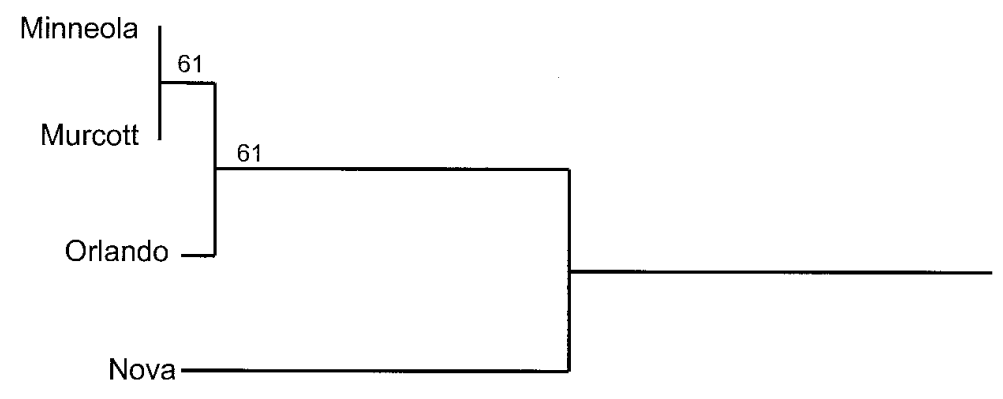

$\mathrm{B}$

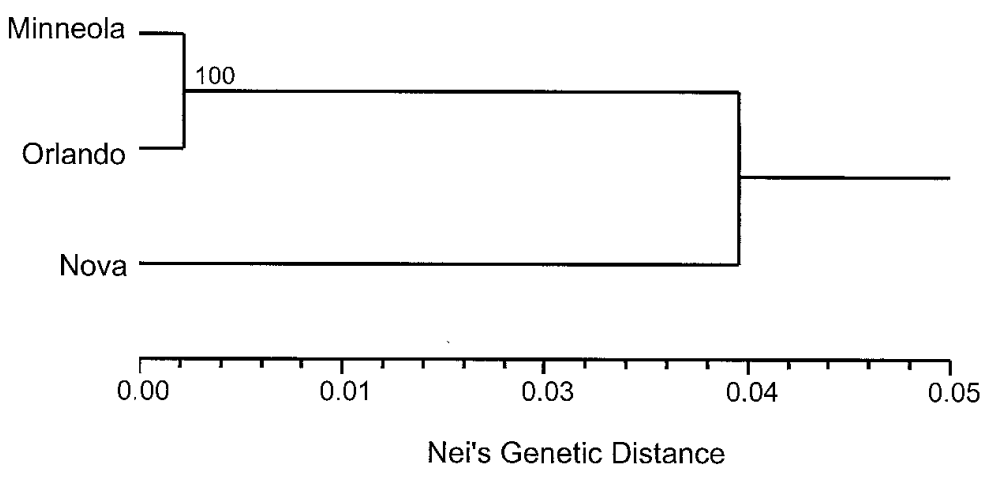

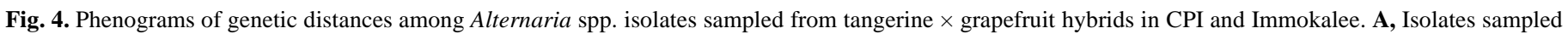

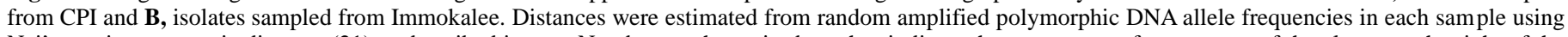

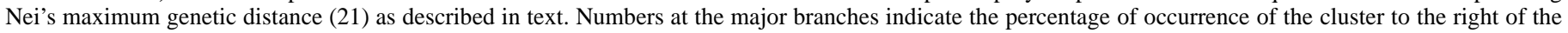
branch in 1,000 bootstrapped dendrograms. Only branches occurring in 50\% or more of the bootstrapped dendrograms (i.e., majority rule consensus tree) are shown. 
We speculate that populations on 'Nova' and grapefruit are in the very early stages of differentiation on these hosts and that any pathogenic differences may have been too small for us to detect. This is supported by the low levels of genetic differentiation observed in this study compared with differences between clearly host-specific isolates from rough lemon and 'Minneola' observed previously (26). Freeman et al. $(8,9)$ similarly failed to detect any differences in pathogenicity among isolates of Colletotrichum gloeosporioides from several different hosts, even though the isolates could be easily differentiated using RAPDs. In the current study, isolates from all citrus hosts had similar disease rankings across the different cultivars, with 'Minneola' always being the most susceptible and grapefruit the most resistant. These laboratory susceptibility rankings correlate well with rankings of susceptibility observed in the field (L. W. Timmer, unpublished data). None of the isolates sampled in this study was pathogenic on rough lemon; however, three grapefruit isolates did produce one lesion each on inoculated rough lemon leaves. No lesions were observed on rough lemon with isolates from 'Minneola' in this and a previous study (26). The susceptibility of grapefruit leaves to brown spot in spray inoculations in the laboratory, but not in the field in Florida, deserves further study. It is possible that the isolates that cause leaf infections on grapefruit in Israel and South Africa are genetically distinct from the isolates present in Florida. Further study of grapefruit isolates from these regions is required.

The host specificity of $A$. alternata and $A$. solani from potato and tomato was recently studied by Weir et al. (40), who demonstrated genetic differentiation between these two fungal species as well as host-related differentiation among isolates of $A$. solani from potato and tomato. Unfortunately, their study did not include pathogenicity assays to confirm that the isolates sampled from each host were host specific. Freeman et al. $(8,9)$ studied the host specificity of Colletotrichum gloeosporioides infecting almond and avocado in Israel and the United States using both molecular markers and pathogenicity tests. It was found that isolates of the pathogen infecting almonds in different geographic regions of Israel had the same multilocus genotype that was distinct from the genotype of isolates infecting avocado. This result suggested that the isolates infecting avocado and almond in Israel are host specific. Pathogenicity studies, however, failed to demonstrate any specificity, as

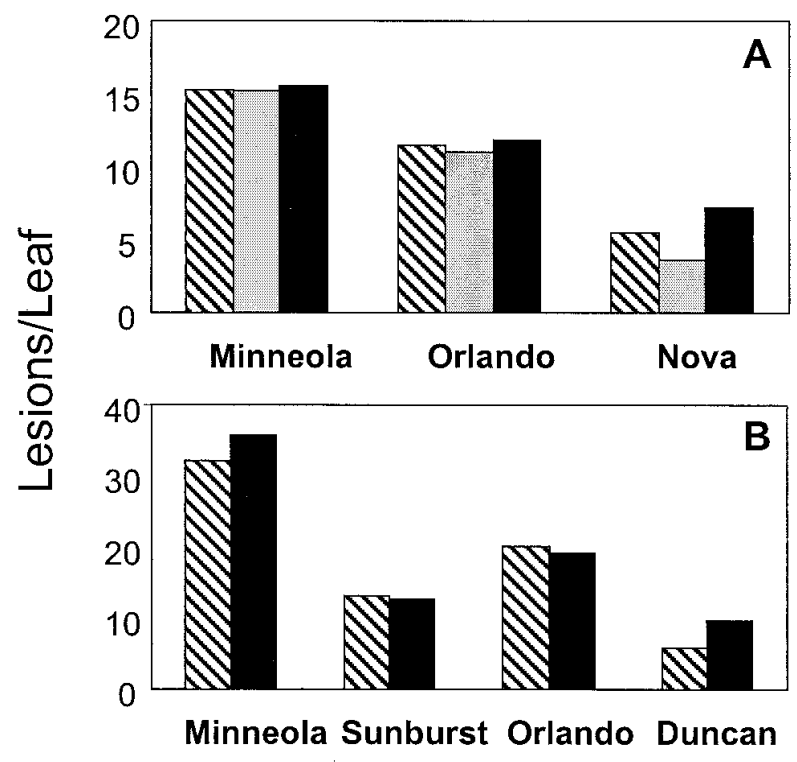

Fig. 5. Pathogenicity of 'Nova' and grapefruit isolates on 'Nova' and grapefruit relative to isolates from other tangerine $\times$ grapefruit hybrids. A, Isolates from 'Minneola' (hatched bars), 'Orlando' (gray bars), and 'Nova' (solid bars) inoculated on 'Minneola', 'Orlando', and 'Nova'. B, Isolates from 'Minneola' (hatched bars) and grapefruit (solid bars) inoculated on 'Minneola', 'Sunburst', 'Orlando', and 'Duncan' grapefruit. isolates from almond and avocado were able to infect both hosts (8). The lack of association between molecular data and pathogenicity data may have been a result of an artificial pathogenicity assay that allowed isolates that would not normally infect a particular host in the field a chance to infect under artificial conditions $(8,9)$. There are several possible explanations for our failure to detect differences in pathogenicity between isolates that were clearly genetically distinct. One possibility is that our pathogenicity assay was not sensitive enough to detect small differences in pathogenicity that might be present in this system. Isolates sampled from rough lemon and 'Minneola' tangelo in a previous study were clearly host specific, causing disease only on one host or the other (26). Another possibility is that our measure of pathogenicity (disease incidence) may not have been truly reflective of differences in pathogen fitness. Future studies of pathogenicity in this system should include other measures of pathogen fitness such as latent period, lesion expansion rates, and sporulation. In the current research, it is possible that we have captured the Alternaria brown spot pathosystem in the very early stages of differentiation on grapefruit and 'Nova' tangerine. With enough time and the accumulation of enough mutations, it is possible that populations of the pathogen will evolve into clearly distinct genetic lineages with more pronounced host specificities.

The low to moderate level of genetic differentiation we observed among populations of Alternaria spp. on 'Minneola' and 'Orlando' tangelos across a wide geographic range in Florida suggests that gene flow has occurred among these locations in the recent past. This result also indicates that geographic substructuring of Alternaria spp. populations is unlikely to have contributed significantly to our observed differentiation among isolates on different cultivars. The homogeneity of Alternaria spp. populations on citrus in Florida is most likely due to the movement of brown spot-infected nursery material among regions when the groves were established. The low but significant level of differentiation we observed is likely due to current restrictions on gene flow among locations and genetic drift within locations. Citrus groves in Florida are often separated by several kilometers, which is beyond the dispersal distance of the pathogen (L. W. Timmer, unpublished data). Samples of isolates from 'Minneola' and 'Orlando' in five locations (one location in common) were similarly differentiated on both hosts. This suggests that populations of the pathogen on 'Minneola' and 'Orlando' may be influenced by similar evolutionary forces. All subpopulations of the pathogen on 'Minneola' and 'Orlando' showed extremely high levels of within-subpopulation genetic diversity with at least two very distinct groups (approximately 60\% similar) observed in every population (26; T. L. Peever, unpublished data). This pattern of high intrapopulation genetic diversity relative to interpopulation diversity indicates that brown spot of citrus is caused by several distinct genotypes of Alternaria. Brown

TABLE 4. Pathogenicity of 'Nova' and grapefruit isolates on 'Nova' or grapefruit relative to isolates from other tangerine $\times$ grapefruit hybrids

\begin{tabular}{|c|c|c|c|c|c|c|}
\hline Exp. & Source & $\begin{array}{c}\text { Degrees of } \\
\text { freedom }\end{array}$ & $\begin{array}{l}\text { Sum of } \\
\text { squares }\end{array}$ & $\begin{array}{l}\text { Mean } \\
\text { square }\end{array}$ & $F$ & $P$ \\
\hline \multirow[t]{5}{*}{1} & Isolate $^{a}$ & 2 & 0.547 & 0.274 & 1.49 & 0.328 \\
\hline & Host $^{\mathrm{b}}$ & 2 & 16.166 & 8.083 & 44.12 & 0.002 \\
\hline & Isolate $\times$ host & 4 & 0.733 & 0.183 & 0.62 & 0.650 \\
\hline & Error & 54 & 15.966 & 0.296 & & \\
\hline & Total & 62 & 33.412 & & & \\
\hline \multirow[t]{5}{*}{2} & Isolate $^{c}$ & 1 & 0.836 & 0.836 & 4.36 & 0.128 \\
\hline & $\operatorname{Host}^{\mathrm{d}}$ & 3 & 39.662 & 13.308 & 69.46 & 0.003 \\
\hline & Isolate $\times$ host & 3 & 0.575 & 0.192 & 0.33 & 0.801 \\
\hline & Error & 100 & 57.334 & 0.573 & & \\
\hline & Total & 107 & & & & \\
\hline
\end{tabular}

a Source of isolate ('Minneola', 'Orlando', and 'Nova').

b Host inoculated ('Minneola', 'Orlando', and 'Nova').

c Source of isolate (Minneola, and 'Marsh' and 'Flame' grapefruit).

d Host inoculated ('Minneola', 'Sunburst', 'Orlando', and 'Duncan' grapefruit). 
spot isolates from 'Minneola' in Florida, Turkey, South Africa, Israel, and Colombia were recently described as seven new species based on morphological criteria (33).

We found no evidence to support the hypothesis that a new grapefruit-specific or 'Sunburst'-specific genotype of the pathogen has been introduced into Florida. The differentiation we observed between grapefruit isolates and hybrid isolates was due to differences in RAPD allele frequencies at the population level. Grapefruit isolates were selected from the same general pool of isolates present on all susceptible cultivars in Florida. The isolates sampled from grapefruit or 'Sunburst' were not genetically unique and could not be distinguished genetically or pathogenically from 'Murcott', 'Minneola', or 'Orlando' isolates over a broad geographic range. There are several possible explanations for the sudden appearance of brown spot on 'Sunburst' in Florida. It is possible that the relatively new plantings of 'Sunburst' were established disease free and have remained free of the pathogen until very recently. A planting of 'Minneola' at the University of Florida Citrus Research and Education Center has remained free of brown spot for over 10 years, despite the presence of several heavily infected 'Minneola' groves less than $1 \mathrm{~km}$ away. This observation suggests that groves can remain free of brown spot for long periods of time if they are beyond the dispersal distance of the pathogen and there is no movement of infected trees into the grove. Another possible explanation for the sudden appearance of brown spot on 'Sunburst' is that the pathogen was present in 'Sunburst' groves at a low level for a number of years but had gone undetected. Particularly favorable environmental conditions for brown spot in 1996 and 1997 may have caused the disease to become a problem on 'Sunburst'. Experimental inoculations have demonstrated that 'Sunburst' is susceptible to brown spot isolates from other hosts, although it does appear to be more resistant than are several other hybrids. The decreased susceptibility of 'Sunburst' relative to other hybrids may have kept brown spot at low levels in Florida until particularly favorable environmental conditions caused the disease to become a problem on this cultivar.

\section{ACKNOWLEDGMENTS}

PPNS No. 0298, Department of Plant Pathology, College of Agriculture and Home Economics Research Center, Project No. 0300, Washington State University, Pullman 99164-6430,. Research supported, in part, by Florida Citrus Production Advisory Council Project No. 961-04 to L. W. Timmer. We thank S. Goodwin and L. Carris for reviewing the manuscript; Y.-C. Liu for programming assistance; H. Darhower and J. Parsons for assistance with the pathogenicity assays, DNA extractions, and polymerase chain reactions; and M. Rubio for maintaining plants in the greenhouse.

\section{LITERATURE CITED}

1. Bliss, D. E., and Fawcett, H. S. 1944. The morphology and taxonomy of Alternaria citri. Mycologia 36:469-502.

2. Brown, J. K. M. 1996. The choice of molecular marker methods for population genetic studies of plant pathogens. New Phytol. 133:183-195.

3. Canihos, Y., Erkilic, A., and Timmer, L. W. 1997. First report of Alternaria brown spot of Minneola tangelo in Turkey. Plant Dis. 81:1214.

4. Castro-Caicedo, B. L., and Montoya-Restrepo, E. C. 1996. Control quimico de la mancha foliar del tangelo Mineola. Cenicafe Av. Tec. 234, Dic. 1996.

5. Cobb, N. A. 1903. Letters on the diseases of plants-Alternaria of the citrus tribe. Agric. Gaz. N.S.W. 14:955-986.

6. Dalkiliç, Z. 1999. Identification and mapping of genes for Alternaria and Phytophthora disease resistance in citrus hybrids. Ph.D. thesis. University of Florida, Gainesville.

7. Doidge, E. M. 1929. A study of some Alternarias affecting citrus in South Africa. Union S. Afr. Dep. Agric. Sci. Bull. 69:1-29.

8. Freeman, S., Katan, T., and Shabi, E. 1996. Characterization of Colletotrichum gloeosporioides isolates from avocado and almond fruits with molecular and pathogenicity tests. Appl. Environ. Microbiol. 62:1014-1020.

9. Freeman, S., Katan, T., and Shabi, E. 1998. Characterization of Colletotrichum species responsible for anthracnose diseases of various fruits. Plant Dis. 82:596-605.

10. Gardner, J. M., Kono, Y., and Chandler, J. L. 1986. Bioassay and hostselectivity of Alternaria citri toxins affecting rough lemon and mandar- ins. Physiol. Mol. Plant Pathol. 29:293-304.

11. Hamelin, R. C., Doudrick, R. L., and Nance, W. L. 1994. Genetic diversity in Cronartium quercuum f.sp. fusiforme on loblolly pines in southern US. Curr. Genet. 26:359-363.

12. Hudson, R. R., Boos, D. D., and Kaplan, N. L. 1992. A statistical test for detecting geographic subdivision. Mol. Biol. Evol. 9:138-151.

13. Hutton, D. G., and Mayers, P. E. 1988. Brown spot of Murcott tangor caused by Alternaria alternata in Queensland. Australas. Plant Pathol. 17(3):69-73

14. Kiely, T. B. 1964. Brown spot of Emperor mandarin. Agric. Gaz. February 1964:854-856.

15. Kohmoto, K., Akimitsu, K., and Otani, H. 1991. Correlation of resistance and susceptibility of citrus to Alternaria alternata with sensitivity to host-specific toxins. Phytopathology 81:719-722.

16. Kohmoto, K., Itoh, Y., Shimomura, N., Kondoh, Y., Otani, H., Kodama, M., Nishimura, S., and Nakatsuka, S. 1993. Isolation and biological activities of two host-specific toxins from the tangerine pathotype of Alternaria alternata. Phytopathology 83:495-502.

17. Kohmoto, K., Scheffer, R. P., and Whiteside, J. O. 1979. Host-selective toxins from Alternaria citri. Phytopathology 69:667-671.

18. Kusaba, M., and Tsuge, T. 1994. Nuclear ribosomal DNA variation and pathogenic specialization in Alternaria fungi known to produce hostspecific toxins. Appl. Environ. Microbiol. 60:3055-3062.

19. Kusaba, M., and Tsuge, T. 1995. Phylogeny of Alternaria fungi known to produce host-specific toxins on the basis of variation in internal transcribed spacers of ribosomal DNA. Curr. Genet. 28:491-498.

20. Kusaba, M., and Tsuge, T. 1997. Mitochondrial DNA variation in hostspecific toxin-producing pathogens in the genus Alternaria. Ann. Phytopathol. Soc. Jpn. 63:463-469.

21. Nei, M. 1972. Genetic distance between populations. Am. Nat. 106:283-292.

22. Nei, M. 1973. Analysis of gene diversity in subdivided populations. Proc. Natl. Acad. Sci. U.S.A. 70:3321-3323.

23. Nishimura, S., and Kohmoto, K. 1983. Host-specific toxins and chemical structures from Alternaria species. Annu. Rev. Phytopathol. 21:87-116.

24. Otani, H., Kohmoto, K., and Kodama, M. 1995. Alternaria toxins and their effects on host plants. Can. J. Bot. 73(suppl. 1):S453-S458.

25. Palm, M. E., and Civerolo, E. L. 1994. Isolation, pathogenicity, and partial host range of Alternaria limicola, causal agent of mancha foliar de los citricos in Mexico. Plant Dis. 78:879-883.

26. Peever, T. L., Canihos, Y., Olsen, L., Ibañez, A., Liu, Y.-C., and Timmer, L. W. 1999. Population genetic structure and host specificity of Alternaria spp. causing brown spot of Minneola tangelo and rough lemon in Florida. Phytopathology 89:851-860.

27. Pegg, K. G. 1966. Studies of a strain of Alternaria citri Pierce, the causal organism of brown spot of Emperor mandarin. Queensl. J. Agric. Anim. Sci. 23:15-28.

28. Ruehle, G. D. 1937. A strain of Alternaria citri Ellis and Pierce causing a leaf spot of rough lemon in Florida. Phytopathology 27:863-865.

29. Schutte, G. C. 1993. Breeding of citrus cultivars resistant to Alternaria alternata: A review. Pages 197-202 in: Proc. IV Congr. Int. Soc. Citrus Nurserymen. The South African Citrus Nurseryman's Association, Nelspruit, South Africa.

30. Schutte, G. C. 1996. First report of Alternaria brown spot on Star Ruby grapefruit in South Africa. Citrus J. 6:24.

31. Simmons, E. G. 1967. Typification of Alternaria, Stemphylium and Ulocladium. Mycologia 59:67-92.

32. Simmons, E. G. 1990. Alternaria themes and variations 27-53. Mycotaxon 37:79-119.

33. Simmons, E. G. 1999. Alternaria themes and variations 226-235: Classification of citrus pathogens. Mycotaxon 70:263-323.

34. Solel, Z. 1991. Alternaria brown spot on Minneola tangelos in Israel. Plant Pathol. 40:145-147.

35. Solel, Z., and Kimchi, M. 1997. Susceptibility and resistance of citrus genotypes to Alternaria alternata pv. citri. J. Phytopathol. 145:389-391.

36. Stoneking, M., Jorde, L. B., Bhatia, K., and Wilson, A. C. 1990. Geographic variation in human mitochondrial DNA from Papua New Guinea. Genetics 124:717-733.

37. Swart, S. H., Wingfield, M. J., Swart, W. J., and Schutte, G. C. 1996. Brown spot of Minneola tangelo and efficacy of fungicidal sprays programmes for disease control in South Africa. Proc. Int. Soc. Citric. 1:379-384.

38. Timmer, L. W., and Peever, T. L. 1997. Managing Alternaria brown spot. Citrus Ind. 78(6):24-25.

39. Timmer, L. W., and Peever, T. L. 1997. Alternaria brown spot found on Sunburst and grapefruit. Citrus Ind. 78(9):46.

40. Weir, T. L., Huff, D. R., Christ, B. J., and Romaine, C. P. 1998. RAPDPCR analysis of genetic variation among isolates of Alternaria solani and Alternaria alternata from potato and tomato. Mycologia 90:813-821.

41. Whiteside, J. O. 1976. A newly recorded Alternaria-induced brown spot disease on Dancy tangerines in Florida. Plant Dis. Rep. 60:326-329. 